\title{
Rethinking AIS: An Innovative Financial Information Systems Curriculum
}

\author{
by \\ Joseph Callaghan, Professor of Accounting \\ Arline Savage, Assistant Professor of Accounting \\ Eileen Peacock, Professor of Accounting
}

Department of Accounting \& Finance

School of Business Administration

Oakland University

Rochester, MI 48309 


\section{ABSTRACT}

This paper describes a new Financial Information Systems curriculum that integrates information technology and financial information in the development of business information systems, and discusses the problems we experienced in establishing the new program. Our intention is to provide accounting graduates with the knowledge they need to leverage the latest information technologies to support the use of financial information in management decision-making, and to integrate financial information and internal controls into business information systems. Our cross-disciplinary approach expands the horizons of our students, from one of viewing accounting as a stand-alone, untimely, inflexible information system, capturing only "accounting transactions" and their limited characteristics, to one of a more realistic real-time, enterprise-wide, activity-driven information system, used by a variety of users with a variety of needs. We also shift the focus from implementing costly controls to that of embedding controls within information systems during systems development, and of continuous systems monitoring. 


\title{
Rethinking AIS: An Innovative Financial Information Systems Curriculum
}

\author{
"In this new marketplace, traditional accountants are a dying \\ breed.... Yet, many accounting educators have failed to restructure \\ accounting curriculum to equip graduates with the tools and \\ expertise they need in today's business world." (Gabbin, 2002, 82)
}

Given the dramatic information technology (IT) changes in the profession, with IT permeating just about every facet of it, there is a strong and growing demand for IT-savvy graduates. Recently, the American Institute of Certified Public Accountants (AICPA) produced a video called "AICPA TopTech 2001 - Critical Elements of Business." Some quotes from this presentation are:

- $\quad$ The traditional accounting firm has changed and is now competing with non-accounting firms - and if they don't make use of information technology, they die."

- $\quad$ The entire accounting profession is in a situation where they have got to become more IT-literate to compete."

- $\quad$ Everything is in electronic form today - your information, my information, your company's information, your client's information and if we don't learn how to protect that, we are all in trouble." 
The foregoing observations demonstrate a need for additional IT teaching in accounting degrees. The curriculum must produce graduates whose understanding goes beyond that of merely using an accounting package to manage data. Rather, graduates must understand the system around which the information is built.

Recently, Albrecht and Sack $(2000,43)$ found that accounting educators are not adequately exposing students to the impact of technology on business. Nor are we teaching them ways in which technology can be leveraged to make business decisions. The new curriculum presented here addresses many of the concerns highlighted by the Albrecht and Sack study. In addition, the objective of this curriculum is to produce graduates who fulfill the market demand suggested by the AICPA (2001) and reiterated by businesses who recruit at our university. This curriculum also recognizes and incorporates feedback received from working professionals, including CPAs, in accordance with Gabbin's (2002, 81-86) recommendations.

This article presents a new framework, six years in the making (1996 to 2002), for an information systems curriculum within the accounting discipline. We created this new major, called "Financial Information Systems" (FIS), in addition to the traditional major. The FIS program is unique in its emphasis on computerized information systems and the fact that it is delivered entirely by retrained accounting faculty. 
Our new program moves away from the title of "Accounting Information Systems," or AIS, currently used to describe an assortment of approaches used in attempts to enhance the IT-literacy of accounting students. The new title implies a broader, enterprise-wide systems orientation, in contrast to viewing the accounting system as one of many enterprise "stovepipe" systems. In addition, we want to avoid some of the preconceptions and unnecessary baggage associated by some with AIS. We take a cross-disciplinary approach to teaching information systems, although we do emphasize systems for performance reporting whose measures are typically expressed in monetary units. We place special emphasis on control systems that are proactive, embedded and in real-time. The accounting profession also seems to be adopting the "financial information systems" terminology, as described in the most recent CPA Letter in the context of providing "financial information systems design and implementation services" (AICPA, 2002, 1,3).

Our purpose is to lay out the architecture and the problems we experienced in establishing the new program. The broad focus of the paper makes a contribution because it provides accounting educators with a relatively detailed description of an innovative curriculum. However, in-depth descriptions of course materials, class projects, and intricate details of particular technologies are beyond the scope of the current paper. Upon request, we will make available course syllabi of 
required FIS courses, sample projects, other course materials, and references to related publications that provide the underlying detail.

The next section highlights the limitations of traditional accounting and information systems programs. The third section explains our new curriculum, designed to address these limitations. The fourth section describes the environment that is necessary to develop, provide and maintain the program. The fifth section deals with obstacles we encountered and explains how we overcame them. The last section concludes the paper.

\section{LIMITATIONS OF EXISTING PROGRAMS}

Over the past 20 years, accounting programs have failed to provide graduates with the skills needed to be an integral part of an enterprise-wide information system. The lack of sufficient information technology content in traditional accounting courses is well known (see, for example, Albrecht and Sack, 2000). Technology, to the extent that it was integrated into the traditional curriculum, was typically via a single, perhaps elective, AIS course. Our challenge was to develop an AIS curriculum that adds value over both traditional accounting and MIS programs.

In AIS courses, there has historically been a lack of consensus. A number of researchers (e.g., Borthick, 1996, 75-86; Groomer and Murthy, 1996, 103-127; Walton, 1997, 69-88) have addressed the issue of how to teach information systems in an accounting context, but no generally accepted framework has evolved. The authors describe existing curricula, document that institutions teach 
AIS very differently, and express the need for curricular reform, while Stewart (1993/4, 3-12) and Callaghan, Peacock and Savage (2001, 51-60) solicit educator and/or practitioner recommendations for appropriate information technology content in accounting courses. Recent literature (e.g., Coe, 2001, 13-24; Fisher 2001, 25-29; Lunsford, 2001, 43-50) continues to espouse a diversity of ideas about what should be included in AIS, demonstrating a continuing lack of consensus.

At our institution, we have a strong and growing MIS program. The increase in MIS enrollment roughly equals the decline in accounting enrollment. However, our MIS program tends to emphasize the managerial aspects over technical proficiency. For instance, a student can complete the program without exposure to hands-on design methods. Our FIS program has as an integral part these very design and construction components, leading to executable accounting-related applications. Consequently, the FIS curriculum adds value in that it provides rigorous and structured content in transaction-based, accounting-related information systems.

The following section describes the evolution of our curriculum development from a single AIS course to a complete FIS curriculum.

\section{NEW FRAMEWORK}

In collaboration with MIS faculty, accounting faculty began to incorporate information systems development into the required AIS course. A successful 
grant application to the National Center for Automated Information Research and the devotion of a sabbatical leave by an accounting faculty member greatly facilitated this innovation. Our initial objectives were to expand students' knowledge of relational databases and to introduce REA modeling (McCarthy, 1979, 667-686; 1982, 554-578; 1999). However, problems surfaced because a single course was insufficient to allow for the desired level of understanding of information systems. The problems were exacerbated because students did not bring sufficient database knowledge into the AIS course to perform at an acceptable level.

As a solution, we decided to add two more AIS courses that would permit the completion of the information systems development lifecycle, which included systems planning, analysis, design and construction. We designed these two courses as accounting electives for an undergraduate or graduate degree track in AIS. To facilitate the expansion of the AIS curriculum from a single course to a sequence of courses, the university approved a new tenure track faculty line. Since we could not find a candidate with the necessary information systems skills, we employed a traditional faculty member who was enthusiastic about being trained in the methods of the new framework. Our dean committed substantial resources to faculty development, and the new hire's professional development included extensive faculty mentoring and external training in systems development methods and associated software, over a two-year period. With these 
resources in place, the final stage of our curricular development resulted in the recent approval of our proposal for the FIS major.

The goal of the new curriculum is to produce information and systems specialists who can integrate financial information and information technology in a business environment. Our intention is to provide graduates with the knowledge they need to:

- Leverage the latest information technologies to support the use of financial information in management, reporting, and decision-making.

- Integrate financial information and internal controls into business information systems, and to monitor these systems.

- Develop cross-functional, enterprise-wide business systems (in planning and analysis), and create transaction-based accounting subsystems (in design and construction). An example of the latter is a fixed asset subsystem, which requires a high degree of accounting technical competence, including depreciation methods, overhead analysis, deferred income taxes, capitalization versus expensing, and an understanding of the arbitrary nature of cost allocation.

Department of Accounting faculty members who have developed financial information systems teaching skills and research interests deliver the new curriculum. In contrast, other institutions have developed information systems curricula with a mix of accounting courses taught by accounting faculty and MIS 
and/or Computer Science courses taught by MIS/Computer Science faculty. Bowling Green State University and Illinois State University are examples of schools using this approach, among others. We believe that our internally developed approach permits better integration of traditional accounting content within business information systems.

The focus of the curriculum is to link accounting theory and practice through the application of information technology. We use a novel approach developed by our faculty to teach FIS concepts by integrating topical areas using a "ModelOriented Tool-Enhanced" framework (Callaghan, Lauer and Peacock, 1998, 5765). The model-oriented aspect uses systems development methods that permit high-level abstractions of real-world information systems. Included are business process (activity), data, and interaction models. The tool-enhanced aspect uses advanced systems development software to convert these models into code executable in many different technical environments. This approach makes it possible to provide an even balance of the conceptual and the practical by leveraging the student's abstraction skills, while concurrently allowing for the construction and implementation of actual information systems (Callaghan, Lauer and Peacock, 1998, 61).

This combined use of models and software permits the leveraging of modeling skills independently from targeted technical environments. Thus, we teach students practical system methods without selecting (and biasing them toward) 
any particular vendor's operating system, database, or programming language. This curricular approach is in dramatic contrast to traditional methods that either ignored technical environments (and were too abstract) or taught only specific technology skills (and were too ephemeral and trade-school-like).

In our business school, the first 60 credits (general education and business pre-core) and the business core are the same for all degrees. The business pre-core includes the traditional accounting principles classes in financial and managerial accounting, and one MIS or Computer Science course. The business core has a second MIS course.

In addition to the general education, core and pre-core requirements, the FIS major has four required courses covering an Introduction to Financial Information Systems and Databases (FIS 301), Financial Information Systems Analysis (FIS 401), Financial Information Systems Design (FIS 402), and Information Systems Audit and Control (FIS 403). Students then choose an additional six credits (two courses) from Financial Information Systems Applications (FIS 404), any accounting course at the 300 or 400 level, any MIS course at the 400 level, any Finance course at the 400 level, and Manufacturing Planning \& Control at the 400 level. We added the last elective for those students who intend to work and develop systems in manufacturing environments. Finally, there is room for two free electives (from any discipline), to complete a 128-credit degree.

A discussion of each of the FIS courses follows: 
- Introduction to Financial Information Systems and Databases (required), focuses on information systems project management, data modeling, database design, querying a database, and using commercial financial databases. The software used in this course could include MS Project, the Oracle $9 \mathrm{i}^{\mathrm{TM}}$ database management system, Edgar, and Compustat. The purpose of this class is to build on the knowledge imparted to students in the core MIS class, and to develop project management and database skills.

\section{Insert Table 1 here}

- Analysis of Financial Information Systems (required), allows students to analyze modern, technologically relevant business information systems. We use the Systems Development Life Cycle (SDLC) as the logical framework, and systems development software such as Oracle Designer ${ }^{\mathrm{TM}}$, Advantage $\mathrm{Gen}^{\mathrm{TM}}$, or Rational Rose ${ }^{\mathrm{TM}}$ to analyze real-world business systems. The students build on database concepts introduced in the first course by developing data, process and interaction models. The existing case materials and assigned projects include a fixed asset subsystem, and a raw materials purchasing subsystem.

Insert Table 2 here

- Design of Financial Information Systems (required) completes the SDLC and continues a project started in the preceding course (Analysis of 
Financial Information Systems). It involves the design and construction of a business information system. Students implement their designs by using Advantage Gen ${ }^{T M}$, Oracle Designer/Developer ${ }^{T M}$, or Rational Rose ${ }^{T M}$. Most of this course is project-based. The purpose of the project is to allow students to actively participate in the full systems development life cycle.

Insert Table 3 here

- Information Systems Audit and Control (required) deals with audit and control aspects of information systems. Students study the risks, controls, and audit techniques related to key information systems areas. In addition, they learn computer fraud detection techniques. Students use ACL Software (with IDEA as an alternative) to perform audit tests and fraud prevention and detection procedures.

Insert Table 4 here

- The content of the Financial Information Systems Applications course (elective) varies to keep pace with changing business needs and information technologies. Topics include XML-XBRL, electronic commerce, executive decision support systems, and emerging technologies. This course is project-based, and permits the student to apply knowledge acquired in prerequisite courses to relevant innovations.

Insert Table 5 here 
The curriculum permits innovation by its design. We designed it to be flexible and attractive to students who would otherwise choose major in either MIS or traditional accounting. It is flexible because it can support a traditional undergraduate accounting major, or it can fit within the 150 credit hour requirement for aspiring CPA's. Despite much criticism of the 150-hour requirements (e.g., Albrecht and Sack, 2000, 30, 33-34; Clikeman, Schwartz and Lathan, 2001, 627-645), these are now a fact of accounting education life in many states. It is important that any degree with some accounting content be considered in the context of the 150-credit hour rule because compliance with this requirement is necessary for a section of the profession. Table 6 illustrates how a student can accomplish this at a school in Michigan.

Insert Table 6 here

This program should be attractive to traditional accounting majors who, with the judicious use of accounting electives, can dual major with only two additional courses. Therefore, we do not expect any cannibalization of our traditional major. Instead, we hope to attract students who would otherwise choose MIS or accounting/information systems programs at other institutions. We believe that potential MIS majors will be attracted to this new major because of the enhanced career opportunities made possible by combining MIS-type technologies with the rigor associated with developing accounting-related subsystems. Our main motivation is not enrollment, but effective accounting education. However, 
increased enrollment should come naturally if we are successful at enhancing the IT skills of our graduates. Appendix A shows an example of how a student might complete the degree over a four-year period.

\section{ENVIRONMENT NEEDED TO PROVIDE THE CURRICULUM}

Resources required to develop, provide and maintain this degree program include hardware, software, faculty with appropriate skills, and support to maintain access to information technology.

Our business school subscribes to corporate university programs. In exchange for a small fee, the university receives basic software and access to training for faculty. We also hired a database administrator to administer the underlying technical infrastructure. His duties include installing and managing the Oracle database, integrating software, including the systems development toolset using the Oracle back-end, and managing other ad hoc software used in the curriculum. This human resource commitment is essential to the delivery of this program. The technical issues involved in installation and maintenance of applications such as Oracle require full-time attention and skills beyond those usually held by computer laboratory staff.

COOL:Gen ${ }^{\mathrm{TM}}$ (now named Advantage Gen ${ }^{\mathrm{TM}}$, and owned by Computer Associates) was the first systems development toolset the business school used for the systems analysis and design classes. We chose this toolset because of (1) its excellent downstream effects in systems development that resulted in the 
generation of application code and the data definition language; (2) the fact that it follows the various stages of the systems development lifecycle lockstep, which provides for a strong theoretical foundation for students; and (3) the excellent free training provided to faculty. However, in light of the popularity of Oracle products in the business world, plus the opportunity to have Oracle Designer ${ }^{\mathrm{TM}}$ as an alternative systems development tool, we decided to subscribe to Oracle's university program as well.

There was much discussion about the pros and cons of each systems development software package. The versatility of the Oracle package, plus the familiarity of the general public with Oracle, helped move the decision somewhat towards the use of Oracle. Currently, our business school supports both packages. In addition, both faculty members involved in this curriculum are currently becoming proficient in the use of Unified Modeling Language (UML)-based toolsets for systems development, and we intend applying these to class projects in the near future. We wish to emphasize that one of the advantages of our approach is that we are vendor-independent, because we do not wish to be wedded to any particular technical environment. The technologies we consider for adoption are intentionally selected for their ability to work with many operating systems, databases and programming languages, thereby better preparing our graduates for the ever-changing IT business world. 


\section{PROBLEMS AND SOLUTIONS}

We experienced many frustrating and time-consuming difficulties with developing and launching the new major. We solved these problems over a sixyear period.

The biggest hurdle was the bureaucratic inertia at the department, business school and university levels in approving the curriculum. Part of the departmental inertia stemmed from Accounting faculty concerns about the potential erosion in the already decreasing number of traditional accounting majors. We eventually persuaded our colleagues that the source of students to the new major would likely come from potential MIS majors, whose department had experienced enrollment increases almost matching the decline in traditional accounting majors. In addition, students can, with judicious selection of electives, dual major in financial information systems and accounting with only two additional courses. Moreover, feedback from our stakeholders, particularly our Accounting and Finance Advisory Board that represents major employers of our graduates, consistently voiced support for this curricular innovation. Without this support, it would have been extremely difficult to convince some very skeptical colleagues.

Another major challenge related to securing faculty members who were both qualified and committed to develop and deliver the new curricular content. We originally had no faculty members with an in-depth knowledge of information systems. Faculty members needed to develop expertise in systems development 
methodologies, and also needed training in the software that supports those methodologies. Initially, one tenured traditional faculty member retooled in the area of information systems. With external grant support and sabbatical leave, he agreed to spearhead the development of a framework and acquire the technical skills through self-study and professional development. For instance, he trained in computer-aided systems engineering methods, data and process modeling, relational database technology, and software engineering concepts. In addition, the new tenure-track faculty member expressed a willingness to retrain in these areas. The incremental cost in terms of new faculty salary and benefits required an initial annual commitment of approximately $\$ 100,000$. The university and business school also committed extensive resources to faculty development, including internal grants, mentoring and training for the new faculty member. We estimate that these costs amounted to approximately $\$ 20,000$.

Another difficulty was the lack of textbook and related student and instructor materials. We were forced to develop our own teaching materials, including extensive use of case materials that provided a projects-based approach to learning. In addition, we developed numerous learning aids. This required a substantial time commitment from faculty, with only nominal out-of-pocket costs to the business school.

Finally, during the first few years, we experienced technical difficulties with the installation and maintenance of commercial software. We obtained funding to 
hire a database administrator (shared with MIS) to administer the underlying technical infrastructure, at an annual cost of approximately $\$ 60,000$.

\section{CONCLUSIONS AND IMPLICATIONS}

There are several reasons to believe that this new curriculum serves the needs of students, employers, and the profession.

First, we evaluated our course materials against the standards espoused by the International Federation of Accountants' International Education Guideline No. 11, "Information Technology In The Accounting Curriculum," which is endorsed by the AICPA (Callaghan, Peacock and Savage, 2000, 1-12). This guideline discusses curriculum relative to a framework of four professional roles for accountants: user, manager, designer and evaluator of information systems. Our Model-Oriented Tool-Enhanced approach "elects a curriculum in support of the designer role.... it permits maximum flexibility to students in terms of providing building blocks for the remaining two roles identified by IFAC.... and it permits a disciplined, normative approach to systems development." (Callaghan, Peacock and Savage, 2001, 52)

Second, we assessed course content by eliciting the perceptions of accounting and IT business professionals about the curriculum (Callaghan, Peacock and Savage, 2001, 51-60). We sent a survey to business professionals who were associated with our business school, either in an advisory, recruiting, alumnus, or sponsorship capacity. The questions included whether or not an item should be 
included the curriculum, and if yes, the extent of inclusion. In general, the conclusion was that the respondents were less in favor of technical hardware, software, and application skill categories, and more in favor of a higher level of abstraction, traditional accounting, and control and business application of IT skills.

Third, before we presented the degree for approval, we asked stakeholders to express their opinions regarding this course. Table 7 contains selected comments from some of the stakeholders about the curriculum. The feedback showed wide support for the program. In addition, the departmental Advisory Board of about 20 finance and accounting professionals expressed enthusiastic support for the new curriculum. The most telling comment from one of these professionals at a recent meeting was: "We will employ as many of these graduates as you can produce."

\section{Insert Table 7 here}

Based on this feedback, we believe that the proposed curriculum will serve the needs of students, regional employers, and the profession. We expect this new curriculum to attract students who would otherwise migrate to the MIS discipline because of the perceived "softness" of the IT component in traditional accounting curricula. We believe that by failing to add sufficient value to the IT skill-set of our graduates, we have failed to keep up with market demands, and have experienced declining student enrollments. In support of this, Albrecht and Sack 
(2000, 9-10) found that graduates who work with technology are paid the highest premiums, with salaries in public and private accounting being the lowest.

The time has come to reengineer accounting curricula so that students have choices with regard to specializations within the profession. Seizing the moment to make needed changes could increase our relevance and open new opportunities for accounting education.

Our technology-rich approach retains the rigor of traditional programs, but we have expanded the horizons of the prospective financial professional from one of viewing accounting as a stand-alone, untimely, inflexible information system, capturing only "accounting transactions" and their limited characteristics, to one of a real-time, enterprise-wide, activity-driven information system, used by a variety of users with a variety of views (requirements). Furthermore, it represents a shift of focus from implementing costly controls to that of embedding controls within information systems during the development phase, and of continuous systems monitoring.

We believe that it is important for traditional accounting educators to take this more expanded view of the discipline, not only in accepting a curriculum like the one we propose, but as importantly, to bring this more expansive view to the traditional accounting curriculum itself. For example, in principles of accounting, one could introduce the notion of how accounting data sits within the overall enterprise database. Intermediate financial and cost accounting could incorporate 
analyses of data from non-accounting sources. In this way, all accounting curricula can move toward a more realistic enterprise-wide approach to problemsolving and decision-making. 


\section{References}

American Institute of Certified Public Accountants. 2002. House Passes Bill to Change Regulation of Accounting Profession. The CPA Letter (June): 1, 3. New York: AICPA.

American Institute of Certified Public Accountants. 2001. AICPA TopTech 2001 Critical Elements of Business (Video tape). Jersey City: AICPA Multimedia Group.

Albrecht, W.J. and R.J. Sack. 2000. Accounting Education: Charting the Course through a Perilous Future. Accounting Education Series No. 16. Sarasota: American Accounting Association.

Borthick, A.F. 1996. Helping Accountants Learn To Get the Information Managers Want: The Role of the Accounting Information Systems Course. Journal of Information Systems 10: 75-86.

Callaghan, J.H., T.W. Lauer, and E. Peacock. 1998. Developing a Comprehensive Curriculum for Accounting Information Systems: A Model-Oriented, Tool-

Enhanced Approach. The Review of Accounting Information Systems 2(4): 57-65.

Callaghan, J.H., E. Peacock, and A. Savage. 2000. Assessment of an Accounting Systems Curriculum: An Analysis of the International Federation of Accountants' Education Guideline No. 11. The Review of Accounting Information Systems 4(1): $1-12$.

Callaghan, J., E. Peacock, and A. Savage. 2001. Feedback on Developing an AIS Curriculum. The Review of Business Information Systems 5(4): 51-60.

Clikeman, P.M., B.N. Schwartz, and M.H. Lathan. 2001. The Effect of the 150Hour Requirement on New Accountants' Professional Commitment, Ethical Orientation, and Professionalism. Critical Perspectives on Accounting 12: 627645.

Coe, M.J. 2001. Using Enterprise Resource Planning Systems As The Core Of An Integrated Accounting Information Systems Course. The Review of Business Information Systems 5: 13-24. 
Fisher, I.E. 2001. The Application of Concept Maps To The Instruction of Accounting Information Systems. The Review of Business Information Systems 5: $25-29$.

Gabbin, A.L. 2002. The Crisis in Accounting Education. Journal of Accountancy (April): 81-86.

Groomer, S.M. and U.S. Murthy. 1996. An Empirical Analysis of the Accounting Information Systems Course. Journal of Information Systems 10: 103-127.

Lunsford, D. 2001. A Senior Level AIS Course Based On The AICPA's Top-Ten Technology Issues. The Review of Business Information Systems 5: 43-50.

McCarthy, W. E. 1979. An Entity-Relationship View of Accounting Models. The Accounting Review (October): 667-686.

McCarthy, W. E. 1982. The REA Accounting Model: A Generalized Framework for Accounting Systems in a Shared Data Environment. The Accounting Review (July): 554-578.

McCarthy, W.E. 1999. Semantic Modeling in Accounting Education, Practice, and Research: Some Progress and Impediments. In Conceptual Modeling: Current Issues and Future Directions, Chen, P., Akoka, J., Kangassalo, H., and Thalheim, B. (Eds.). Berlin and Heidelberg: Springer Verlag.

Stewart, J.R. 1993/4. Educator/Practitioner Recommendations for Computer Usage in an Undergraduate Accounting Information Systems Course. The Journal of Computer Information Systems 34: 3-12.

Walton, K.S. 1997. Current Approaches to Structuring the Information Systems Curriculum for Accounting Majors. Accounting Educators' Journal 9: 69-88. 


\section{APPENDIX A: SAMPLE CURRICULUM}

First semester (16 crs)

Composition 1 (4)

Linear Programming (4)

Information Technology (4)

General Education Course (4)

Third semester (16 crs)

Financial Accounting (4)

Macroeconomics (4)

General Education Course (4)

General Education Course (4)

Fifth semester(14 crs)

Marketing (4)

Organizational Behavior (3)

Managerial Finance I (4)

Management Information Systems (3)
Second semester (16 crs)

Composition II (4)

Calculus for Social Sciences (4)

Public Speaking (4)

General Education Course (4)

Fourth semester (18 crs)

Managerial \& Cost Accounting (4)

Microeconomics (4)

Statistical Methods (6)

General Education Course (4)

Sixth semester (17 crs)

Operations Management (4)

Human Resource Management (3)

Introduction to FIS and Databases (3)

Intermediate Financial Accounting I (3)

General Education Course (4)

Eighth semester (16 crs)

Management Strategy \& Policies (4)

FIS Design (3)

Information Systems Audit\&Control (3)

Managerial \& Cost II (Free Elective) (3)

FIS Analysis (3)

ss (3)

Intermediate Financial Accounting II (3) Federal Income Tax (Free Elective) (3)

Total: 129 credits

Note: Our institution imposes the four-credit hour courses included in this sample curriculum upon us. 


\section{TABLE 1}

FIS 301: INTRODUCTION TO FINANCIAL INFORMATION SYSTEMS

\section{AND DATABASES}

Course description: This course focuses on information systems project management, data modeling, database design, database queries, and using commercial financial databases.

Prerequisites: Introductory Managerial, Business pre-core and core MIS courses.

\section{Course objectives:}

1. Identify weaknesses and limitations inherent in traditional accounting systems architectures.

2. Describe an event-driven framework for a technology-enabled financial information system.

3. Define the stages of the systems development life cycle.

4. Describe and discuss pros and cons of contemporary approaches to systems development.

5. List the steps necessary for effective and efficient project planning and management.

6. Generate basic data models using computer software.

7. Query a database to generate financial reports.

8. Extract data from a commercial financial database. 
TABLE 1 (continued)

FIS 301: INTRODUCTION TO FINANCIAL INFORMATION SYSTEMS \&

\section{DATABASES}

Major topics: Limitations of traditional accounting information system architectures; the event-driven relational database model as an information technology solution; the Input-Process-Storage-Output framework for process modeling; managing business and information processes in an IT environment; the Systems Development Life Cycle framework; Information Engineering and UML approaches to systems development; project planning and management; basic data modeling and database design; querying a database; using commercial financial databases.

Information technology: Students use an interactive Internet learning tool to identify relationships between entity types in data modeling, they query a relational database using SQL, and they use commercial financial databases (e.g., Edgar, Compustat) for project completion.

Oral communication: Students must participate in class discussions. For each class session, students complete a participation sheet on which (s)he records the "best" verbal comment or contribution. They hand this sheet to the instructor each week for grading. Students present their project findings in class.

Writing skills: Weekly assignments contain written components. 
TABLE 1 (continued)

FIS 301: INTRODUCTION TO FINANCIAL INFORMATION SYSTEMS \&

\section{DATABASES}

Critical thinking: Students to extract data from databases when answering assignment and project questions.

Problem solving: Students use information they believe is relevant to make decisions about projects and other assignments. They must justify their solutions.

Team building: Students work in groups on a semester-long case project. 
TABLE 2

FIS 401: ANALYSIS OF FINANCIAL INFORMATION SYSTEMS

Course description: The knowledge acquired in this course will help students to analyze modern, technologically-relevant financial information systems. We use the Systems Development Life Cycle (SDLC) as a logical framework, and systems development software such as Oracle Designer ${ }^{\mathrm{TM}}, \mathrm{COOL}: \mathrm{Gen}^{\mathrm{TM}}$, or Rational Rose ${ }^{\mathrm{TM}}$ to analyze real-world business systems.

Prerequisites: FIS 301- Introduction to Financial Information Systems \& Databases

\section{Course objectives:}

1. Define activity and process modeling and list advantages of these models.

2. Describe a relational database management system and perform normalization of data.

3. Develop REA models.

4. Prepare activity (process) models.

5. Construct data models and describe data structures and attributes of the database repository.

6. Use a systems development toolset for systems planning and analysis.

7. Apply the SDLC to simulate real-life planning and analysis situations. 
TABLE 2

FIS 401: ANALYSIS OF FINANCIAL INFORMATION SYSTEMS

Major topics: Information Engineering and UML approaches to systems development; activity (process), data and interaction modeling; using systems development software to perform financial information systems analysis.

Information technology: We use a computer laboratory and each student has a computer. Students use contemporary systems development software to analyze and model financial information systems.

Oral communication: Students must participate in class discussions and presentations. For each class session, a student records the "best" verbal comment or contribution made during class on a class participation sheet, which is graded. Writing skills: Students complete assignments with written components. Critical thinking: A case-based approach is used to build critical thinking skills. Each week, students sift through large amounts of case information. They are required the extract the information that is important for solving case questions.

Problem solving: Students use the information they believe is relevant to make decisions about cases and other assignments, and justify their solutions. They analyze a real business situation, developing process and data models.

Team building: After individual case preparation at home, students are assigned to small groups to discuss and reach small group solutions for class discussion. 
TABLE 3

\section{FIS 402: DESIGN OF FINANCIAL INFORMATION SYSTEMS}

Course description: This course involves the design and construction of financial information systems, using a Model-Oriented-Tool-Enhanced approach to systems development. Designs are implemented using Advantage Gen ${ }^{\mathrm{TM}}$, Oracle Designer/Developer ${ }^{\mathrm{TM}}$, or Rational Rose ${ }^{\mathrm{TM}}$. A large portion of this course is casebased. The purpose of the project is to allow students to actively participate in the full systems development life cycle.

Prerequisites: FIS 401 - Analysis of Financial Information Systems

Course objective: Design and construct a functional financial information system, and populate it with data.

Major topics: Analysis review; advanced modeling; design overview; dialog design; graphic user interface design; generating and testing applications.

Information technology: The students use information technology throughout this course, which is conducted in a computer laboratory. Each student has a computer. Students use contemporary systems development software to design and construct business systems.

Oral communication: All students are required to participate in class discussions in each class. This is an essential component of learning with cases. Students also present their case findings to the class. 
TABLE 3 (continued)

FIS 402: DESIGN OF FINANCIAL INFORMATION SYSTEMS

Writing skills: Students complete written assignments and reports.

Critical thinking: The case-based approach builds critical thinking skills.

Students sift through large amounts of information. They extract the information

that is important for solving the case questions.

Problem solving: Students use the information they believe is relevant to make decisions about cases and other assignments. Students justify their solutions.

Team building: Students work in groups on a semester-long case project. 
TABLE 4

\section{FIS 403: INFORMATION SYSTEMS AUDIT AND CONTROL}

Course description: This course covers advanced topics that are important to professional accountants, and deals with audit and control aspects of information systems. Students study risks, controls, and audit objectives related to key information systems areas, as well as computer fraud detection techniques. They use generalized audit software for audit tests and fraud detection.

Prerequisites: FIS 301 - Introduction to Financial Information Systems \& Databases

\section{Course objectives:}

1. Identify the risks and control issues associated with modern information systems, and to develop strategies to control for these risks.

2. Define the audit role of Computer Assisted Audit Tools and Techniques.

3. Use ACL software as a data extraction and analysis tool to perform audit and fraud detection tests.

Major topics: Information technology and internal control; computer Fraud and Security; regulatory environment for E-commerce; risk of insecure E-commerce systems; E-commerce risk management; cryptography and authentication; firewalls; Internet payment systems; auditing computer-based information systems; Computer Assisted Audit Tools and Techniques; using software for data extraction and analysis (including fraud detection). 
TABLE 4

FIS 403: INFORMATION SYSTEMS AUDIT AND CONTROL

Information technology: Students use $\mathrm{ACL}^{\mathrm{TM}}$, an audit software package, to query, analyze and report on data stored by a computer system.

Oral communication: All students are required to participate in class discussions. Students record their "best" contributions on a participation sheet that is graded. Students present projects to the class throughout the semester. Topics include: Network Security; Firewall Audit; Application of Biometrics; Digital Analysis as an Auditing Tool; Extensible Business Report Language (XBRL); Auditing in a Paperless Environment.

Writing skills: Written assignments and audit reports.

Critical thinking: Students are required to access data from a computer files and to comment on anomalies or unusual trends.

Problem solving: Students test, analyze and report on the data that they extract from a computer system, and make audit and control decisions. Students are required to justify each decision.

Team building: After doing individual assignment preparation at home, students are assigned to small groups to discuss individual solutions and to reach a small group solution, which is then presented to the class. Also, students work on projects in groups. 


\section{TABLE 5}

\section{FIS 404: FINANCIAL INFORMATION SYSTEMS APPLICATIONS}

Course description: The content of this course varies to keep pace with changing business needs and information technologies. Topics include XML-XBRL, electronic commerce, executive decision support systems, and new technologies as they emerge. This course will be entirely project-based.

Prerequisites: FIS 402 - Design of Financial Information Systems

Course objective: To use the latest information technologies to build complex financial information systems.

Information technology: The students make use of the latest relevant information technology throughout this course, which is conducted in a computer laboratory. Each student has a computer in class.

Oral communication: All students participate in regular class discussions, and present their case projects at various stages.

Writing skills: The case projects contain written components.

Critical thinking: The complex case-based projects build critical thinking skills.

Problem solving: Students use the information they believe is relevant to make decisions about case projects and other assignments. Students are required to justify their solutions.

Team building: Students work in groups on a semester-long case project. 


\section{TABLE 6 \\ 150-HOUR REQUIREMENT}

The AICPA rule for eligibility to sit for the CPA examination requires 150 semester hours of education at an accredited institution, including a bachelor's degree or its equivalent. Individual states add their regulations to the requirements, both to the types of credits required to be eligible for the exam, and for a license to practice. In general terms, the proposed curriculum is 128 credits, therefore 22 will be required beyond the degree. States are usually quite specific about the particular type of credits required for eligibility for the exam and for a licensee to practice. The following will show how this program, developed for a school in Michigan, can be used as a basis for a program of 150 credit hours.

In Michigan, there are two sets of rules: requirements to write the CPA exam and requirements to be licensed to practice.

To write the exam: "Applicants for the Uniform CPA Examination are required to have a baccalaureate degree with a concentration in accounting from an accredited college or university, consisting of 24 semester hours of accounting principles, including auditing, and 24 semester hours of general business subjects. The accounting principles include study in financial accounting, managerial accounting including cost accounting, accounting systems and controls, United States federal taxation, and governmental/fund accounting." 


\section{TABLE 6 (continued) \\ 150-HOUR REQUIREMENT}

How can the FIS proposal deal with these requirements? The FIS degree requires the accounting systems credits. The financial accounting classes can come from the designated electives, and two of the remaining four requirements can be covered by free electives e.g. the managerial accounting, including cost and taxation. This leaves governmental/fund accounting and auditing as two classes that a student would need to write the exam.

To practice: (1). "A masters degree in accounting or a master of business administration (MBA) that includes not less than 12 semester hours of graduate level accounting, or (2) 30 semester hours of accounting subjects, including no more than 6 semester hours of taxation, and 39 semester hours, including a minimum of 3 semester hours each in business communications and computer technology and a minimum of 3 semester hours, but not more than 12 semester hours, in at least 5 of the following areas: business law, economics, ethics, finance, management, marketing, taxation, statistics, and business policy."

The FIS degree requires 128 credits, therefore an additional 22 credits are required. However, looking at the state requirements, only one more credit in accounting is needed beyond the requirements to write the exam. 


\section{TABLE 7}

\section{SELECTED STAKEHOLDER COMMENTS}

Student: "Their curriculum is integrated and advanced and truly teaches today's accounting students useful skills for reaching success in their chosen profession.

The acquired tools such as information engineering principles, data-modeling techniques, and systems life cycle development work greatly increased my knowledge and interest in modern information systems. I believe these courses supply accounting students with additional knowledge which distinguishes them from other graduates."

Student: "I have a fairly extensive background in accounting systems and systems development, but I have yet to see another learning approach that has been as effective at merging conceptualization and actualization. Although technology is constantly changing, it is still extremely beneficial to gain experience using a tool of some sort in addition to teaching the concepts. This two-pronged method of instruction lays out a good foundation while reinforcing the theories with handson use. I have since been able to use the skills gained in this class to assist in current work related projects." 
TABLE 7 (continued)

\section{SELECTED STAKEHOLDER COMMENTS}

Student: "In my current position, I am creating a fixed asset relational database and have to gather information from people in accounting, finance and management. To help the accounting and financial people understand what is needed from them, I'm using the approach that I learned in my [FIS] course. I've just started my career in MIS and have already used material from [my FIS class] and I'm sure that I will continue to in the future. The process modeling and data modeling concepts taught in the curriculum transcend the accounting profession, and teach students how to be value-added business people in any disciplines.

Students completing this curriculum benefit from a challenging and practical IS experience, and they also take with them a sound methodology for analyzing business processes and data stores. In simple terms, the MOTE framework provides accounting students with exceptional cross-functional systems analysis and design skills. The combination of financial and systems analysis skills is a highly sought after skill set in the current job market. As a consulting manager, I had the opportunity to utilize the skills I gained from the program on almost a daily basis. The program definitely provided me with a skills-set that was superior to my peers in the accounting profession." 
TABLE 7 (continued)

\section{SELECTED STAKEHOLDER COMMENTS}

Industry: "As a previous Senior Vice President of Finance of a large multinational corporation, I see a real need for people with the skills learned in this curriculum. The fact that these skill sets are based on a framework, and not tied to any particular technology, makes for a more flexible employee. In a corporate environment where flexibility with respect to business change, technological change, and exposure to different cultures can make the competitive difference, such flexibility is extremely important. As an employer of several graduates and interns of this curriculum, I see a positive difference in their performances, particularly in their ability to consider a variety of approaches to problems. A professional with the ability to better abstract and model underlying business reality, is in a better position to offer workable solutions than those professionals with only narrowly-defined skills, wedded to particular technologies. I believe the curriculum advanced here serves students and the profession well in this regard." 
TABLE 7 (continued)

\section{SELECTED STAKEHOLDER COMMENTS}

Academic: "In my view, Professors Callaghan et al.'s framework is significantly different from traditional approaches. In the information technology age, accounting students are required to understand more than just how $\mathrm{G} / \mathrm{L}$ files are processed within the computer, and how spreadsheet and database software can be used to replace manual, labor-intensive, and tedious work. They must be able to integrate their knowledge and skills to develop IT-enabled and reengineered business processes, and learn to make strategic use of accounting information embedded in these processes. In my view, the curriculum developed by Professors Callaghan et al. is important for business education in the sense that it provides business students with critical knowledge and skills in the new millennium, including the integration of AIS and business process modeling, and IT-enabled business process reengineering." (Professor of Information Systems at a university in Massachusetts.) 